\title{
Voltammetric monitoring of laccase-catalysed mediated reactions
}

\author{
César Fernández-Sánchez ${ }^{\mathrm{a}}$, Tzanko Tzanov ${ }^{\mathrm{a}}$, Georg M. Gübitz ${ }^{\mathrm{b}}$, Artur Cavaco-Paulo ${ }^{\mathrm{a}, *}$ \\ ${ }^{a}$ Department of Textile Engineering, Campus de Azurem, University of Minho, 4800 Guimarães, Portugal \\ ${ }^{\mathrm{b}}$ Department of Environmental Biotechnology, Graz University of Technology, Petergasse 12, A-8010 Graz, Austria
}

Received 13 February 2002; received in revised form 13 June 2002; accepted 18 June 2002

\begin{abstract}
Six different compounds capable of mediating laccase-catalysed reactions have been tested by cyclic voltammetry. They exhibited quasireversible electrodic behaviour with formal redox potentials ranging from 150 to $800 \mathrm{mV}$ ( $E^{0 \prime}$ vs. SCE). The immersion of a laccase-coated glassy carbon electrode (GCE) in mediator solutions generated large cathodic catalytic currents easily recorded by cyclic voltammetry at lowpotential scan rates. This current showed two well-defined $\mathrm{pH}$ profiles, which correlated with the variation of the mediator redox potentials at the $\mathrm{pH}$ range tested. The relevant effect of temperature on the activity of laccase has been assessed here. Likewise, it was shown that the current record varied with the substrate concentration. This trend fitted Michaelis-Menten kinetics, which allowed us to give an estimation of the affinity of the fungal laccase for the different mediators.
\end{abstract}

(C) 2002 Elsevier Science B.V. All rights reserved.

Keywords: Laccase; Mediator; Cyclic voltammetry; Catalytic current; Immobilisation

\section{Introduction}

During the past decades, oxidoreductases enzymes have attracted the efforts of many research groups in the environmental and biotechnological field because of their great potential to remove pollutants and catalyse a great variety of redox processes with no hazardous side effects.

Laccase (EC 1.10.3.2) is the generic name given to a family of multicopper oxidases that are able to oxidise many different substrates with the concomitant reduction of dioxygen to water. The laccase molecule is a dimeric or tetrameric glycoprotein usually containing four copper atoms per monomer distributed in three redox sites (one in each $\mathrm{T} 1$ and $\mathrm{T} 2$ sites, and two in $\mathrm{T} 3$ site). It is assumed that laccase catalysis firstly involves $\mathrm{T} 1 \mathrm{Cu}$ reduction by the substrate, followed by internal electron transfer from $\mathrm{T} 1 \mathrm{Cu}$ to $\mathrm{T} 2$ and $\mathrm{T} 3 \mathrm{Cu}$ and, finally, dioxygen reduction at $\mathrm{T} 2$ and $\mathrm{T} 3$ sites [1].

Although these enzymes exhibit a specific affinity for oxygen as their electron acceptor, their specificity towards their reducing substrates is rather low [2]. Laccases catalyse the removal of a hydrogen atom from the hydroxyl group of ortho- and para-substituted mono- and polyphenolic sub-

\footnotetext{
* Corresponding author. Tel.: +351-53-510280; fax: +351-253-510293.

E-mail address: artur@det.uminho.pt (A. Cavaco-Paulo).
}

strates and from aromatic amines by one electron abstraction to form free radicals capable of undergoing further laccasecatalysed oxidation or non-enzymatic reactions such as hydration of polymerisation [3].

The capability of laccase to degrade chromophore substrates such as triarylmethane, indigoid, azo, and anthraquinonic dyes suggests a potential application of the enzyme in textile dye bleaching processes $[4,5]$. However, these processes have been hindered due to unfavourable kinetics between the enzyme and the dye. The use of small molecules capable to act as electron transfer mediators between the enzyme and the dye has been regarded as a feasible solution to this important drawback [6].

Laccase-mediated systems (LMS) have been applied to many other processes, which include pulp delignification [7-10], oxidation of organic pollutants [11] and the development of biosensors [12-14] or biofuel cells [15]. Several organic and inorganic compounds have been reported as effective mediators for the above purposes. These include thiol and phenol aromatic derivatives, $\mathrm{N}$-hydroxy compounds and ferrocyanide, respectively.

When mediators are incorporated in laccase-assisted processes, the electron transfer from the mediator to the enzyme is followed by electron donations from the target molecule to oxidised mediator, which give rise to the regeneration of the mediator $[6,16,17]$. In this context, not only laccase substrates but also other compounds capable of 
undergoing indirect catalytic oxidation reactions can be treated with LMS.

It has been reported that the feasibility of these molecules as effective electron donors is governed by the redox potential difference between the laccase and mediator, which strongly depends on the $\mathrm{pH}$ at which the reaction takes place. For substrates whose oxidation does not involve proton exchange, the laccase activity decreases as the $\mathrm{pH}$ increases, whereas for those mediators whose oxidation involves proton exchange, the $\mathrm{pH}$ activity profile depends on the type of laccase rather than substrate [18-20]. But the catalytic activity of the enzyme has also been regarded to be strongly dependent upon the interaction between a specific laccase and the mediator $[9,21]$.

Studies done on the effectiveness of these molecules in laccase-assisted reactions involved the spectrophotometric detection of their corresponding oxidation species at an appropriate wavelength or the measurement of the oxygen consumption in air-saturated solutions with an $\mathrm{O}_{2}$ electrode $[7,9,11,18-21]$. However, few studies have been done based on the use of voltammetric detection systems. Monitoring of mediated laccase interactions can be easily carried out by recording the redox processes that mediators undergo. Electrochemical techniques can be used with a variety of samples, i.e. turbid and coloured samples, in batch or flow processes with a relatively simple and easy to use instrumentation.

$\mathrm{Xu}$ et al. [19] carried out voltammetric studies to elucidate the redox chemistry of various $N$-hydroxy compounds used as laccase substrates or different redox couples applied for the estimation of the redox potential at the $\mathrm{T} 1$ site of several laccases [21]. Likewise, Bourbonnais et al. [8] carried out a thorough voltammetric study of the redox chemistry of two different laccase mediators and their interaction with lignin model compounds, in which a glassy carbon electrode (GCE) simulates the laccase activity towards both electron donors. Voltammetric studies of a truncated laccase were also accomplished and the rate of heterogeneous electron transfer between the enzyme and the working electrode was calculated [22]. In addition, the laccase reduction of dioxygen to water in the presence of different redox mediators has been studied in other voltammetric applications such as biofuel cells [15] and biosensors [12-14].

The aim of this work was to study the interaction of a Trametes villosa laccase with six different commercially available mediators by means of cyclic voltammetry. These were the organic compounds ABTS, syringaldazine, acetosyringone, promazine, hydroquinone and the inorganic compound ferrocyanide. All of them were chosen due to the suitable electrodic behaviour that they showed at different potentials, which are within a wide potential window. A comparative investigation of the effect of experimental parameters, such as $\mathrm{pH}$ and temperature, as well as an estimation of Michaelis-Menten kinetic parameters may help us elucidate the suitable experimental conditions for an effective catalysis of the different enzyme-mediator systems proposed.

\section{Materials and methods}

\subsection{Chemicals}

Fungal laccase (benzenediol/oxygen oxidoreductase: EC 1.10.3.2) from T. villosa (Polyporus pinsitus) (NS $51002, \mathrm{PpL}, 9 \mathrm{mg} / \mathrm{ml}$ ) was kindly supplied by Novo Nordisk (Denmark) and stored at $4{ }^{\circ} \mathrm{C}$. This was used as received without doing any previous dilution. $2,2^{\prime}$-Azinobis(3-ethylbenzothiazoline-6-sulfonic acid) (ABTS), 3',5'dimethoxy-4'-hydroxyacetophenone (acetosyringone), 10-[3-(dimethylamino)propyl]-phenothiazine (promazine), 4-hydroxy-3,5-dimethoxybenzaldehyde azine (syringaldazine), 1,4-benzenediol (hydroquinone), potassium ferrocyanide were from Sigma (Spain) and used as received. All other chemicals were of reagent grade. Solutions of the different mediators were prepared in either $0.1 \mathrm{M}$ acetate buffer $\mathrm{pH} 5$ or Britton-Robinson buffer of different $\mathrm{pHs}$ immediately before use. Syringaldazine exhibit low solubility in aqueous solutions so that it was dissolved in a buffer-ethanol mixture prepared in a proportion 1:1 (v/v) and its $\mathrm{pH}$ adjusted with sodium hydroxide.

\subsection{Cyclic voltammetry}

Cyclic voltammetric experiments were performed with a Voltalab 40 PGZ301 potentiostat (Radiometer Analytical, France) and controlled by Voltamaster 4 software, version 2.1. All measurements were carried out in a $50-\mathrm{ml}$ thermostated cell, model BEC/EDI, with a conventional threeelectrode configuration. A working glassy carbon electrode (GCE), with a surface diameter of $3 \mathrm{~mm}$, was used together with a platinum wire counter electrode and a saturated calomel reference electrode (SCE). The whole system was purchased from Radiometer. Before each experiment, the surface of the glassy carbon electrode was polished on a diamond-polishing pad followed by a thorough washing step with distilled water.

\subsection{Measurement procedures}

Voltammetric responses were recorded in $40 \mathrm{ml}$ of substrate solutions of concentration varying from 0.2 to 1 $\mathrm{mM}$, prepared in acetate buffer $\mathrm{pH}$ 5. Potential was scanned from -200 to $1000 \mathrm{mV}$ vs. SCE, after holding the electrochemical system at the initial potential for $10 \mathrm{~s}$. The GCE was always thoroughly rinsed with distilled water and polished after every single experiment.

The protocol followed for the recording of the catalytic current generated by the enzyme oxidation of the different substrates was as follows. A $5-\mu 1$ sample of the enzyme solution was dropped onto the polished surface of the 
working electrode and allowed to dry for $15 \mathrm{~min}$ at room temperature. Next, the electrode was dipped in the electrochemical cell containing $0.2 \mathrm{mM}$ substrate solution prepared with $0.1 \mathrm{M}$ acetate buffer $\mathrm{pH} 5$, unless otherwise stated. After holding the system at the initial potential for $10 \mathrm{~s}$, voltammograms were recorded by scanning the potential in the cathodic direction in a window where the substrate underwent a redox process, at a scan rate of $5 \mathrm{mV} / \mathrm{s}$. Voltammograms in the absence of laccase were recorded in the same way. Catalytic currents were estimated as the difference between both currents. Single experiments were always carried out, which involved performing a cleaning step (rinse in diluted $\mathrm{NaOH}$ solution and distilled water), followed by a polishing and new enzyme coating of the working electrode for each experiment. The substrate solution was also discharged after one measurement and $40 \mathrm{ml}$ of a fresh substrate solution were added to the electrochemical cell. All these experiments were done at room temperature.

Following the same protocol as described above, the dependence of the substrate formal potential, determined as the mean value of the anodic and cathodic peak potentials $\left(E^{0 \prime}\right)$ and the catalytic current on $\mathrm{pH}$ was studied. Substrate solutions $(0.2 \mathrm{mM})$ were prepared in B-R buffers in a $\mathrm{pH}$ range $2-8$.

The influence of temperature on the catalytic current was studied by varying the temperature of the thermostated electrochemical cell between 30 and $60{ }^{\circ} \mathrm{C}$. Substrate solutions $(0.2 \mathrm{mM})$ were prepared in B-R buffers at optimised $\mathrm{pH}$ values.

The study of the dependence of the substrate concentration on the catalytic current was carried out for the estimation of kinetic parameters. Cyclic voltammograms were recorded in substrate solutions of different concentration ranged between 0.02 and $1 \mathrm{mM}$ under previously optimised experimental conditions. Data fitted to the following adaptation of the Michaelis-Menten equation [23]:

$I=\frac{I_{\max }[\mathrm{S}]}{[\mathrm{S}]+K_{\mathrm{m}}^{\mathrm{app}}}$.

$[\mathrm{S}]$ is the bulk concentration of the mediator, $I$ and $I_{\max }$, the catalytic current and maximum catalytic current, respectively, and $K_{\mathrm{m}}^{\mathrm{app}}$, the apparent Michaelis-Menten constant. $I$ $\max$ and $K_{\mathrm{m}}^{\mathrm{app}}$ were calculated from Hanes-Woolf linearisation of the above equation.

\section{Results}

\subsection{Cyclic voltammetry of mediators}

All the substrates tested have been shown previously to be effective electron donors in the laccase-catalysed reduc-
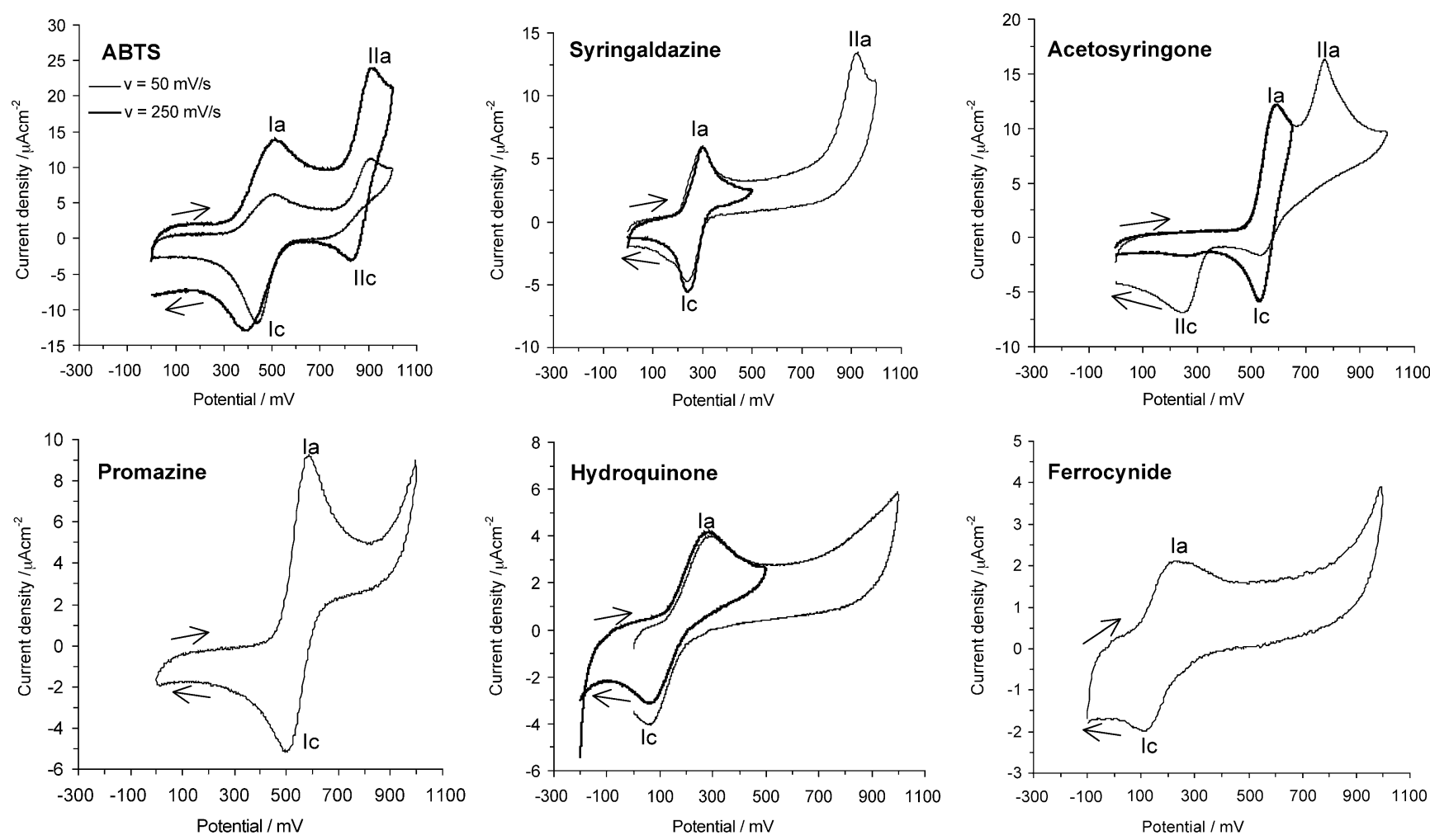

Fig. 1. Cyclic voltammograms of mediators recorded in buffered solutions $\mathrm{pH}$. Concentration of ABTS, acetosyringone and promazine $=1$ mM. Concentration of syringaldazine, hydroquinone and ferrocyanide $=0.2 \mathrm{mM}$. Potential was measured versus a SCE. Scan rate was $50 \mathrm{mV} / \mathrm{s}$ except for a voltammogram of ABTS. 
tion of dioxygen to water $[6-8,10,15-17]$. The feasibility of the voltammetric detection of their interaction with this enzyme implies the following assessments. (a) Each mediator undergoes redox reactions, at the working electrode which give rise to either quasi-reversible or reversible electrodic processes within a suitable potential window. This correlates with the fact that, (b) both oxidised and reduced species of the corresponding redox pair should be stable chemically and do not inhibit the enzymatic reaction.

The electrochemistry of these molecules was tested at the GCE. Resulting voltammograms are shown in Fig. 1. All the mediators generate well-shaped almost reversible or quasireversible signals with peak potential separation values $\left(\Delta E_{\mathrm{p}}\right)$ between 75 and $245 \mathrm{mV}$ and formal potentials $\left(E^{0 \prime}\right)$ between 150 and $800 \mathrm{mV}$ (vs. SCE). Chemical stability of the different redox species generated in the corresponding electrodic processes is confirmed by the anodic to cathodic peak ratio $\left(i_{\mathrm{pa}} / i_{\mathrm{pc}}\right)$, which approaches to 1 in all cases.

Voltammograms of ABTS were recorded at two different scan rates, following the study previously reported by Bourbonnais et al. [8]. At a scan rate of $250 \mathrm{mV} / \mathrm{s}$, two anodic and two cathodic peaks were recorded, which correspond to the oxidation/reduction of $\mathrm{ABTS} \mathrm{ABTS}^{+}$(Ia/ Ic) and $\mathrm{ABTS}^{+} / \mathrm{ABTS}^{2+}$ (IIa/IIc) redox pairs $\left(E^{0 \prime}\right.$ are 444 and 873 vs. SCE, respectively). At a scan rate of $50 \mathrm{mV} / \mathrm{s}$, only one cathodic process was observed, which shows significant higher peak current than its anodic counterpart. As reported previously, this behaviour is related to the comproportionation reaction between ABTS and $\mathrm{ABTS}^{2+}$ to give the cation radical $\mathrm{ABTS}^{+}$, which leads to the disappearance of the cathodic process due to the reduction of $\mathrm{ABTS}^{2+}$. This reaction is not favoured at high scan rates. The cation radical did not undergo any couple chemical reaction, as it was verified by the recording of slow scan voltammograms in a potential window where the second anodic process (IIa) takes place. Thus, similar reversible processes $(\mathrm{Ia} / \mathrm{Ic})$ to that shown at a high scan rate were observed, with anodic to cathodic current ratios around 1 in all cases.

Voltammograms of syringaldazine show a nearly reversible process (Ia/Ic) with a $E^{0 \prime}$ of $270 \mathrm{mV}$ (vs. SCE) and a second anodic peak at a potential of $+0.8 \mathrm{~V}$ (vs. SCE). Peak currents of the reversible process recorded in the full potential window almost did not differ from those obtained when the scan was done in a window where only the reversible process was observed, which demonstrated the independent nature of both processes.

Acetosyringone underwent two oxidation processes at potentials around +0.6 (Ia) and $+0.8 \mathrm{~V}$ vs. SCE (IIa). When the potential sweep was done from 0 to $+1.0 \mathrm{~V}$, a well-defined reduction process was observed at around +0.2 $\mathrm{V}$ vs. SCE (IIc). However, a second cathodic peak was
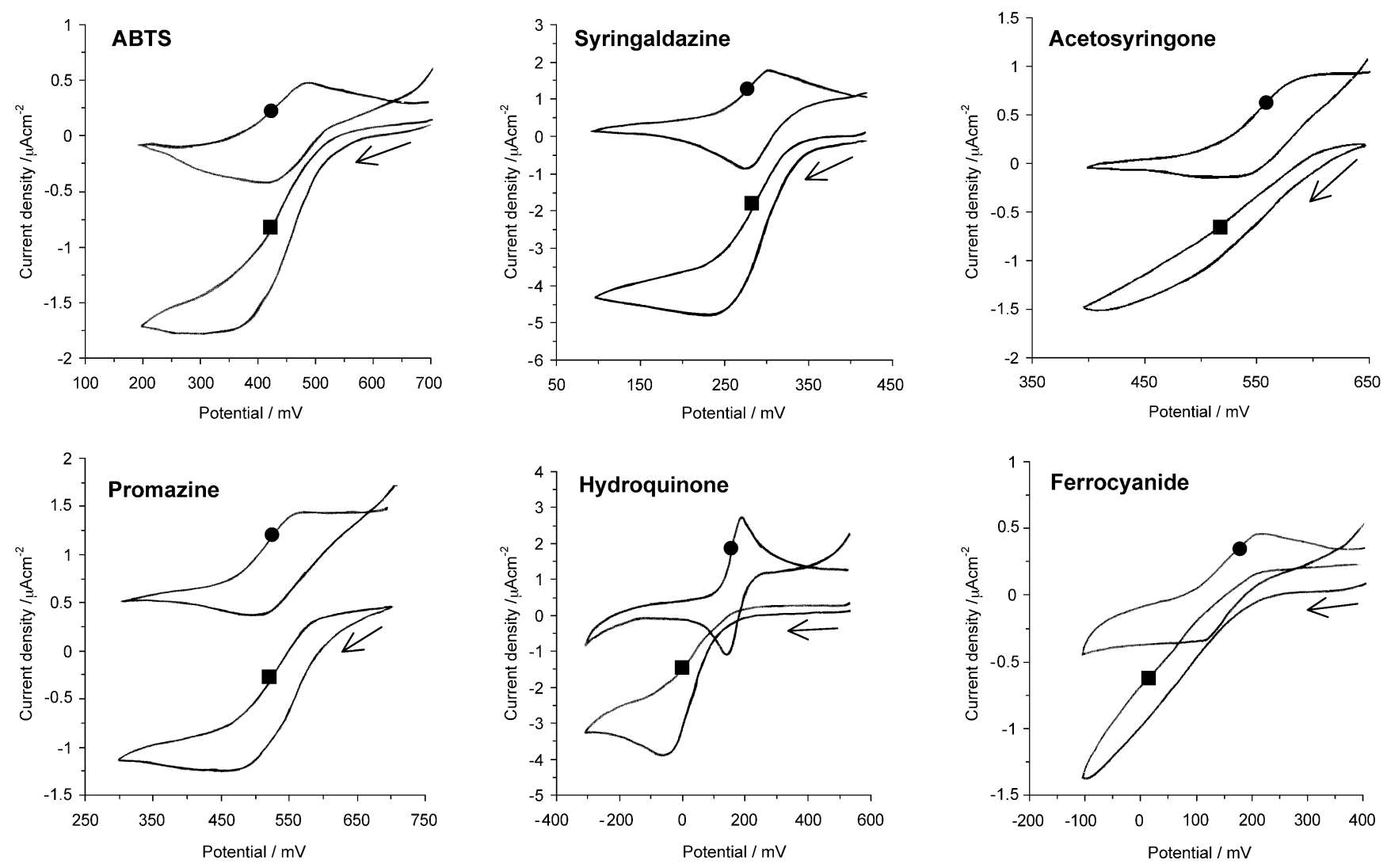

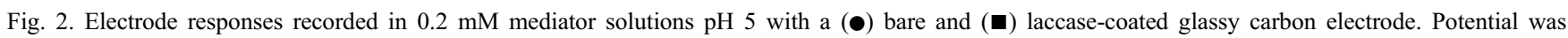
measured versus a SCE. Scan rate: $5 \mathrm{mV} / \mathrm{s}$. Arrows indicate the starting direction of the scan. Other experimental conditions are described in detail in text. 
recorded when the scan was reversed at $+0.6 \mathrm{~V}$ (Ic), which forms a reversible redox pair with peak Ia $\left(E^{0 \prime}=560 \mathrm{mV}\right.$ vs. SCE). Multiple cyclic scans done in the full potential window showed a third anodic process at around $+0.3 \mathrm{~V}$ (vs. SCE), which form a second reversible signal with peak IIc (data not shown). Currents of both peaks of this reversible signal were higher as the number of cycles increased, while currents of Ia and IIa were lower. This was not observed when multiple scans were applied in a potential window up to $+0.6 \mathrm{~V}$, which suggests that this phenomenon is related to a polymerisation process of the resulting oxidised species formed in process IIa.

Voltammetric signals of promazine, hydroquinone and ferrocyanide show single quasi-reversible processes (Ia/Ic) recorded at the GCE, with $E^{0 \prime}$ of 540,170 and $165 \mathrm{mV}$ (vs. $\mathrm{SCE}$ ) and $\Delta E_{\mathrm{p}}$ values of 105,240 and $120 \mathrm{mV}$, respectively.

\subsection{Voltammetric detection of laccase-catalysed oxidation of mediators}

Enzyme-mediated reactions were carried out in substrate solutions at oxygen non-saturating conditions. The affinity of laccase for oxygen is high, with a binding constant between 0.01 and $0.02 \mathrm{mM}[14,24]$. Since it was reported that the oxygen concentration in water at air and at room temperature is about $0.26 \mathrm{mM}$ [14], all the active sites of the enzyme are saturated with oxygen in water solutions. Therefore, the catalytic current measured only depends on the mediator concentration. In the same context, oxygen content in the reaction medium was kept constant by means of using fresh substrate aliquots for each experiment.

As described in the experimental section, laccase was directly adsorbed on the surface of the GCE. This resulted in a weak immobilisation of the enzyme. The recording of lower peak currents to those obtained in the previous scans when multicycle scans were performed with the same electrode proved a slow detachment of the immobilised enzyme. However, electrodes modified in this way were suitable for carrying out single measurements in a reproducible manner. This involved the replacement of the electrode coating after one experiment.

Slow-scan voltammograms recorded in $0.2 \mathrm{mM}$ substrate solutions $\mathrm{pH} 5$ with both bare and laccase-coated GCEs are shown in Fig. 2. A significant change in the shape of the corresponding signals of each mediator was observed. All of them are characterised by the disappearance of the anodic process due to the catalytic but no electrodic oxidation of the mediator, and a significant enlargement of the cathodic process related to the reduction of the oxidised form of the mediator generated by the enzymatic reaction. The shape of these voltammograms is typical of catalytic redox processes taking place at the electrode solution interface, which has been widely described in the literature. Steady-stated values of the cathodic current were always observed except for ferrocyanide. Further studies explained below also showed the typical sigmoidal shape for this substrate at other $\mathrm{pH}$ values. Laccase activity was not observed at potential values of the second reversible oxidation of ABTS corresponding to $\mathrm{ABTS}^{+} / \mathrm{ABTS}^{2+}$ redox pair. It was previously reported that this catalytic process can take place but it is too slow to be detected by cyclic voltammetry [8].

Fig. 3A shows the $\mathrm{pH}$ profiles of the catalytic currents of these mediators. Two different trends are clearly observed. ABTS and ferrocyanide currents decreased as the $\mathrm{pH}$ of the solution increased, while currents recorded with hydroquinone, promazine and syringaldazine, acetosyringone exhibited a maximum value at $\mathrm{pH}$ intervals of $3-5$ and $5-6$, respectively. At $\mathrm{pH}$ values above 6 , the activity of the enzyme towards all substrates seemed to decay rapidly, these being negligible at $\mathrm{pH} 8$. A correlation between these
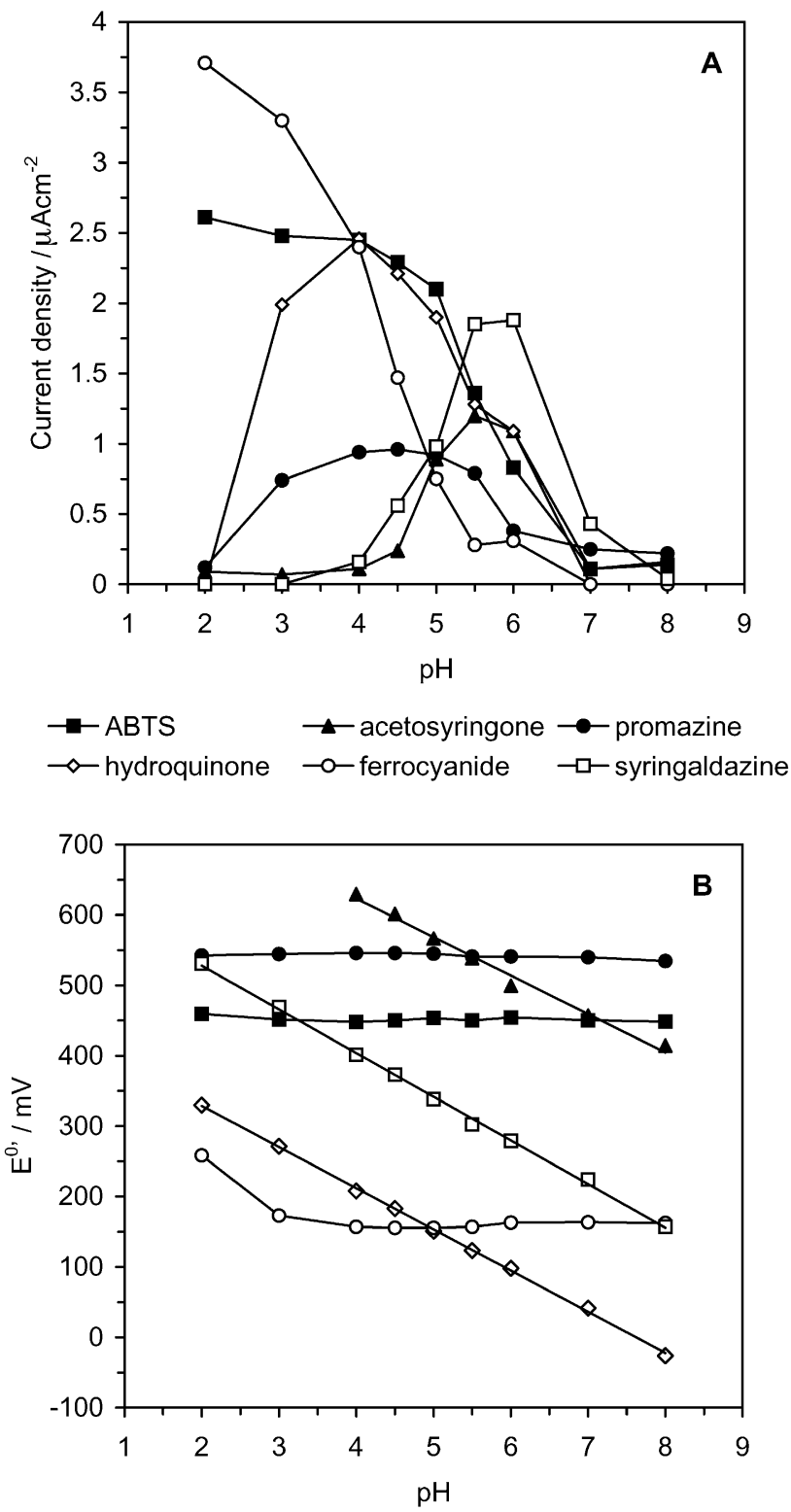

Fig. 3. (A) Dependence of the catalytic current on pH. (B) Formal redox potential of mediators as a function of $\mathrm{pH}$. Absolute values of catalytic current were plotted. Experimental conditions are given in text. 
profiles and the influence of $\mathrm{pH}$ on $E^{0 \prime}$ of the different mediators (Fig. 3B) is likely to exist, except for promazine. The $E^{0 \prime}$ of ABTS, ferrocyanide and promazine remain constant in the $\mathrm{pH}$ range studied, whereas the potentials of the other mediators shift to more negative values as the $\mathrm{pH}$ increases. This variation is linear and fits to the following equations. Acetosyringone: $E^{0 /}=-54.6 \mathrm{pH}+841.8$. Syringaldazine: $E^{0 \prime}=-62.1 \mathrm{pH}+652.2$. Hydroquinone: $E^{0 \prime}=-58.5 \mathrm{pH}+446.0$. The values of the negative slopes are near the Nernstian value of $59 \mathrm{mV} / \mathrm{pH}$ unit, which indicate that their redox processes involve the same number of protons as electrons.

As it is perfectly known the activity of laccases is strongly dependent on the temperature $(T)$. It has been previously reported that this influence is significantly different for laccases of different origin [21]. Here, we studied the variation of the catalytic current with $T$ with the six mediators, and profiles are shown in Fig. 4. It was found out that the optimum $T$ for a maximum activity of the $T$. villosa laccase used in this work should be between 40 and $50{ }^{\circ} \mathrm{C}$. However, when this study was performed with ferrocyanide and hydroquinone, a decrease in the current measured was observed as the $T$ increased. This behaviour is likely to be related to the lack of thermal stability of their corresponding solutions.

The oxidation of these molecules catalysed by this fungal laccase exhibited typical Michaelis-Menten kinetics in terms of the mediator concentration. Kinetic parameters were estimated from the data obtained by monitoring the influence of the mediator concentration on the catalytic current at optimum experimental conditions. These data was further fitted to a linear graph by means of the

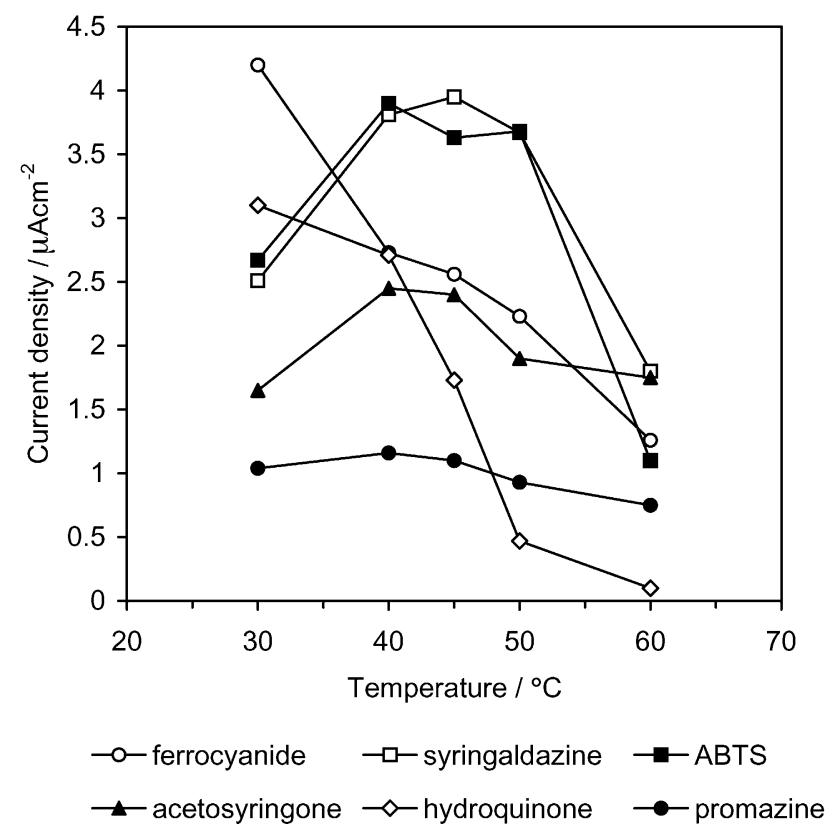

Fig. 4. Dependence of the catalytic current on temperature. Absolute values of catalytic current were plotted. Experimental conditions are given in text.
Table 1

Estimated kinetic parameters for each laccase mediator

\begin{tabular}{lcllll}
\hline Substrate & $\begin{array}{l}I_{\max }^{\mathrm{a}} \\
\left.(\mu \mathrm{A} \mathrm{cm})^{-2}\right)\end{array}$ & $\begin{array}{l}K_{\mathrm{m}}^{\mathrm{app}} \\
(\mathrm{mM})\end{array}$ & $\begin{array}{l}I_{\max } / K_{\mathrm{m}}^{\mathrm{app}} \\
\left(\mu \mathrm{A} \mathrm{cm} \mathrm{cm}^{-2} / \mathrm{mM}\right)\end{array}$ & $r$ & $\mathrm{n}$ \\
\hline ABTS & 7.07 & 0.13 & 54.38 & 0.9994 & 6 \\
Syringaldazine & 9.85 & 0.21 & 46.90 & 0.9976 & 5 \\
HQ & 9.02 & 0.24 & 37.58 & 0.9920 & 4 \\
Promazine & 2.72 & 0.28 & 9.71 & 0.9990 & 4 \\
Ferrocyanide & 16.18 & 0.37 & 43.73 & 0.9945 & 4 \\
Acetosyringone & 2.70 & 0.11 & 24.50 & 0.9955 & 4 \\
\hline
\end{tabular}

Experimental conditions of $\mathrm{pH}$ and $T$ for each reaction were those previously optimised.

${ }^{\text {a }}$ Absolute values of maximum catalytic currents.

Hanes-Woolf equation (see experimental section). Results are shown in Table 1 . The $I_{\max } / K_{\mathrm{m}}{ }^{\text {app }}$ ratio allows the estimation of the affinity of the enzyme for each molecule. Higher values would indicate a better effectiveness of the laccase-mediated reduction of oxygen to water. In this context, ABTS appears to be the best mediator among those studied, whereas promazine showed a poor interaction with this laccase enzyme.

\section{Discussion}

From a thermodynamic point of view, useful electron donors in laccase-catalysed reactions should have a reduction potential between that of oxygen and the reduction potential of the type I copper of the laccase. Therefore, the fungal laccase used in this work is likely to show a $\mathrm{T} 1$ site redox potential higher than $560 \mathrm{mV}$ (vs. SCE) which is the formal potential of acetosyringone. From the voltammograms in Fig. 1, it can be affirmed that the different electrochemical states of these mediators are stable and show nearly reversible electrodic behaviour, which makes them useful for the voltammetric monitoring of laccasemediated reactions. The stability of the different redox species of a laccase mediator is very important when LMS are applied to different industrial processes since, as it was described in the Introduction, it is known that the actual oxidant of the target molecule is the oxidised form of the mediator, but not the enzyme itself.

The interaction between the different mediators and the enzyme was easily monitored by recording slow-scan voltammograms as those depicted in Fig. 2. This takes place in two steps: (a) a catalytic chemical step where the enzyme oxidises the mediator and (b) an electrodic step that involves the reduction and regeneration of the oxidised mediator. If higher scan rates were applied, an oxidation peak was observed, which is likely to be related to the electrodic oxidation of the remaining substrate not previously oxidised by the enzyme within the time scale imposed by the potential scan. ABTS oxidation by a laccase [8] and bilirubin oxidase [25] has been previously monitored by cyclic voltammetry in solutions containing both the medi- 
ator and the enzyme. Results were comparable to those reported in this work. Although the rest of molecules have shown to be effective mediators with laccase, to our knowledge, no other studies have dealt with the use of voltammetric techniques for the monitoring of these reactions.

It is shown that these interactions strongly depend on the $\mathrm{pH}$ of the solution where they take place. The $\mathrm{pH}$ profiles observed for ABTS, ferrocyanide, syringaldazine and acetosyringone are in agreement with those previously reported with this laccase [20]. As it was pointed out above, the redox chemistry of these mediators plays an important role in their interaction with the enzyme. For those whose oxidation does not involve proton exchange (ABTS, ferrocyanide and promazine), the $\mathrm{pH}$ profile exhibits a negative slope as the $\mathrm{pH}$ increases. Nevertheless, if proton exchange takes place in this reaction (syringaldazine, acetosyringone and hydroquinone), the $\mathrm{pH}$ profile shows a maximum in the $\mathrm{pH}$ range studied. For hydroquinone, this maximum appears to be at more acidic pHs than that for the other two mediators.

Apart from the significant change in the catalytic current, differences in the shape of the electrodic responses were also observed. This fact was dramatic in the case of ferrocyanide. At $\mathrm{pHs}$ lower than 4, the faradaic current reached a steady-state value, corresponding to an equilibrium state between the enzyme-mediator and reduced mediator-electrode charge transfers, similar to those shown in Fig. 2 with other compounds. As the $\mathrm{pH}$ increases, a change in the slope of the recorded curve was observed and the shape appeared to be the one presented in the abovereferred figure. It was reported that cyanide inhibits the activity of this enzyme [15] by irreversible coordination to the copper sites of laccase. This fact could contribute in different extent as the $\mathrm{pH}$ increases, which would lead to this unexpected voltammetric behaviour.

The variation of the laccase activity with $\mathrm{pH}$, showed in terms of the change of the catalytic current measured, would be affected by different factors depending on the mediator used. Thorough studies previously reported by $\mathrm{Xu}$ et al. $[1,9,18-20]$ evidenced a clear relationship between the enzyme activity and the potential difference between its active $\mathrm{T} 1$ site and the formal potential of the mediator $\left(\Delta E^{*}\right)$. Moreover, the $\mathrm{OH}^{-}$contribution to this activity profile should be taken into consideration. Results shown in this work corroborate this statement. It has been reported that the redox potential of the T1 site of this enzyme is almost independent on $\mathrm{pH}[20]$. Thus, for ABTS and ferrocyanide, $\Delta E^{*}$ keeps constant at different $\mathrm{pH}$ values and consequently, the first factor is not relevant. However, the $\mathrm{OH}^{-}$inhibition of the internal electron transfer between the $\mathrm{T} 1$ and $\mathrm{T} 2$ sites of laccase provokes the recording of lower catalytic currents at higher $\mathrm{pH}$ values. Promazine, whose oxidation does not also imply proton release either, exhibited a different behaviour. The catalytic current remained nearly constant in a $\mathrm{pH}$ range of 3-5.5, with a decreasing at both lower and higher $\mathrm{pHs}$ out of this interval.
The catalytic process with this mediator is probably not affected in great extent by the $\mathrm{pH}$ of the solution at which it takes place. Moreover, if it is taken into account that the currents recorded are quite low, it can be suggested that the affinity of this laccase towards promazine is not very significant and could be the cause of this unexpected $\mathrm{pH}$ profile. The $\Delta E^{*}$ value for hydroquinone, acetosyringone and syringaldazine will be higher as the $\mathrm{pH}$ increases. Thus, this factor played a major contribution to the catalytic current measured in acidic solutions. At near neutral and alkaline $\mathrm{pHs}$, the $\mathrm{OH}^{-}$inhibition is important, both factors giving rise to these bell-shaped profiles.

On the other hand, the kinetics of mediated laccasecatalysed reactions is firstly affected by the affinity between the enzyme and the mediator. An estimation of this influence can be done by voltammetric measurements in terms of $I_{\max } / K_{\mathrm{m}}^{\text {app }}$ ratio. These parameters are often calculated in the design of enzymatic sensors to evaluate the sensitivity of the system proposed, which is related to the low or high affinity of an enzyme towards a specific substrate $[23,26]$. Lower $K_{\mathrm{m}}^{\mathrm{app}}$ values at similar catalytic currents involved higher effectiveness of the enzyme at lower mediator concentrations. Based on these facts, ABTS would be chosen as the most suitable substrate for the T. villosa laccase used in this work for future applications (Table 1). However, as it was pointed out elsewhere [9], the same order of effectiveness observed here could be completely different for other fungal laccases, which should be calculated empirically.

Finally, we would like to remark that many practical applications of laccases in industrial processes should involve the immobilisation of these enzymes on different supports. The use of macro-electrodes inserted in flow electrochemical macro-cells might be very adequate supports for these treatments, since they would allow the online monitoring of the activity of this enzyme in a very easy manner and with a relatively simple and cheap instrumentation. This work would involve thorough studies of methodologies of immobilisation, estimation of activities of immobilised laccases on electrode supports of different materials, as well as the design of suitable flow electrochemical cells.

\section{References}

[1] L. Gianfreda, F. Xu, J.-M. Bollag, Laccases: a useful group of oxidoreductive enzymes, Bioremediat. J. 3 (1999) 1-25.

[2] F. Xu, Laccase, in: M.C. Flickinger, S.W. Drew (Eds.), Encyclopedia of Bioprocess Technology: Fermentation, Biocatatysts and Bioseparation, Wiley, New York, 1999, pp. 1545-1554.

[3] A.I. Yaropolov, O.V. Skorobogatko, S.S. Vartanov, S.D. Varfolomeyev, Laccase - properties, catalytic mechanism, and applicability, Appl. Biochem. Biotechnol. 49 (1994) 257-280.

[4] E. Abadulla, T. Tzanov, S. Costa, K.-H. Robra, A. Cavaco-Paulo, G.M. Gübitz, Decoloration and detoxification of textile dyes with a laccase from Trametes hirsuta, Appl. Environ. Microbiol. 66 (2000) 3357-3362.

[5] R. Campos, A. Cavaco-Paulo, K.-H. Robra, M. Schneider, G. Gübitz, 
Indigo degradation with laccases from Polyporus sp. and Sclerotium rolfsii, Textile Res. J. 71 (2001) 420-424.

[6] H.P. Call, I. Mücke, History, overview and applications of mediated lignolytic systems, especially laccase-mediator systems (Lignozym ${ }^{\circledR}$ process), J. Biotechnol. 53 (1997) 163-202.

[7] R. Bourbonnais, M.G. Paice, B. Freiermuth, E. Bodie, S. Borneman, Reactivities of various mediators and laccases with kraft pulp and lignin model compounds, Appl. Environ. Microbiol. 63 (1997) $4627-4632$

[8] R. Bourbonnais, D. Leech, M.G. Paice, Electrochemical analysis of the interactions of laccase mediators with lignin model compounds, Biochim. Biophys. Acta 1379 (1998) 381-390.

[9] K. Li, F. Xu, K.-E. Eriksson, Comparison of fungal laccases and redox mediators in oxidation of a nonphenolic lignin model compound, Appl. Environ. Microbiol. 65 (1999) 2654-2660.

[10] C. Crestini, D.S. Argyropoulos, The early oxidative biodegradation steps of residual kraft lignin models with laccase, Bioorg. Med. Chem. 6 (1998) 2161-2169.

[11] P.J. Collins, M.J.J. Kotterman, J.A. Field, A.D.W. Dobson, Oxidation of anthracene and benzo[a]pyrene by laccases from Trametes versicolor, Appl. Environ. Microbiol. 62 (1996) 4563-4567.

[12] F. Trudeau, F. Daigle, D. Leech, Reagentless mediated laccase electrode for the detection of enzyme modulators, Anal. Chem. 69 (1997) $882-886$.

[13] J. Kulys, A. Drungiliene, U. Wollenberger, K. Krikstopaitis, F. Scheller, Electroanalytical determination of peroxidases and laccases on carbon paste electrodes, Electroanalysis 9 (1997) 213-218.

[14] B.A. Kuznetsov, G.P. Shumakovich, O.V. Koroleva, A.I. Yaropolov, On applicability of laccase as label in the mediated and mediatorless electroimmunoassay: effect of distance on the direct electron transfer between laccase and electrode, Biosens. Bioelectron. 16 (2001) 73-84.

[15] G. Tayhas, R. Palmore, H.-H. Kim, Electro-enzymatic reduction of dioxygen to water in the cathode compartment of a biofuel cell, J. Electroanal. Chem. 565 (1999) 110-117.

[16] C.L. Chen, A. Potthast, T. Rosenau, J.S. Gratzl, A.G. Kirkman, D. Nagai, T. Miyakoshi, Laccase-catalysed oxidation of 1-(3,4-dime- thoxyphenyl)-1-propene using ABTS as mediator, J. Mol. Catal., B Enzym. 8 (2000) 213-219.

[17] A. Potthast, T. Rosenau, K. Fischer, Oxidation of benzyl alcohols by the laccase-mediator system (LMS) - a comprehensive kinetic description, Holzforschung 55 (2001) 47-56.

[18] F. Xu, Oxidation of phenols, anilines, and benzenethiols by fungal laccases: correlation between activity and redox potentials as well as halide inhibition, Biochemistry 35 (1996) 7608-7614.

[19] F. Xu, J.J. Kulys, K. Duki, K. Li, K. Krikstopaitis, H.-J.W. Deussen, E. Abbate, V. Galinyte, P. Schneider, Redox chemistry in laccasecatalysed oxidation of $N$-hydroxy compounds, Appl. Environ. Microbiol. 66 (2000) 2052-2056.

[20] F. Xu, Effects of redox potential and hydroxide inhibition on the pH activity profile of fungal laccases, J. Biol. Chem. 272 (1997) 924-928.

[21] F. Xu, W. Shin, S.H. Brown, J.A. Wahleithner, U.M. Sundaram, E.I. Solomon, A study of a series of recombinant fungal laccases and bilirubin oxidase that exhibit significant differences in redox potential, substrate specificity, and stability, Biochim. Biophys. Acta 1292 (1996) 303-311.

[22] M. Gelo-Pujic, H.-H. Kim, N.G. Butlin, G.T.R. Palmore, Electrochemical studies of a truncated laccase produced in Pichia pastoris, Appl. Environ. Microbiol. 65 (1999) 5515-5521.

[23] A. Lindgren, L. Stoica, T. Ruzgas, A. Ciucu, L. Gorton, Development of a cellobiose dehydrogenase modified electrode for amperometric detection of diphenols, Analyst 124 (1999) 527-532.

[24] J. Rodakiewicz-Nowak, S.M. Kasture, B. Dudek, J. Haber, Effect of various water-miscible solvents on enzymatic activity of fungal laccases, J. Mol. Catal., B Enzym. 11 (2000) 1-11.

[25] S. Tsujimura, H. Tatsumi, J. Ogawa, S. Shimizu, K. Kano, T. Ikeda, Bioelectrocatalytic reduction of dioxygen to water at neutral $\mathrm{pH}$ using bilirubin oxidase as an enzyme and 2,2'-azinobis(3-ethylbenzothiazolin-6-sulfonate) as an electron transfer mediator, J. Electroanal. Chem. 496 (2001) 69-75.

[26] A. Narváez, G. Suárez, I.C. Popescu, I. Katakis, E. Domínguez, Reagentless biosensors based on self-deposited redox polyelectrolyteoxidoreductases architectures, Biosens. Bioelectron. 15 (2000) 43-52. 